Research Paper

\title{
Icariin Decreases the Expression of APP and BACE-I and Reduces the $\beta$-amyloid Burden in an APP Transgenic Mouse Model of Alzheimer's Disease
}

\author{
Lan Zhang, Cong Shen, Jin Chu, Ruyi Zhang, Yali Li, Lin Li ${ }^{\bowtie}$ \\ Department of Pharmacology, Xuanwu Hospital of Capital Medical University, Key Laboratory for Neurodegenerative Diseases of Ministry \\ of Education, Beijing 100053, China.
}

\begin{abstract}
$\square$ Corresponding author: Department of Pharmacology, Xuanwu Hospital of Capital Medical University, 45 Chang-chun Street, Beijing 100053, China. Tel.: +86-10-83198886; Fax: +86-10-63042809; E-mail: lanizhg@hotmail.com (L. Zhang), linli97@hotmail.com (L. Li)

(C) Ivyspring International Publisher. This is an open-access article distributed under the terms of the Creative Commons License (http:/ / creativecommons.org/ licenses/by-nc-nd/3.0/). Reproduction is permitted for personal, noncommercial use, provided that the article is in whole, unmodified, and properly cited.
\end{abstract}

Received: 2013.03.11; Accepted: 2013.12.24; Published: 2014.01.21

\begin{abstract}
Objective: The purpose of this study was to investigate the effects and pharmacological mechanisms of icariin, which is the main component in the traditional Chinese herb Epimedium, on $\beta$-amyloid $(A \beta)$ production in an amyloid precursor protein (APP) transgenic $(\mathrm{Tg})$ mouse model of Alzheimer's disease (AD).

Methods: APPV7I7I Tg mice were randomly divided into a model group and icariin-treated (30 and $100 \mu \mathrm{mol} / \mathrm{kg}$ per day) groups. Learning-memory abilities were determined by Morris water maze and object recognition tests. $A \beta$ contents were measured by enzyme-linked immunosorbent assays and immunohistochemistry. Amyloid plaques were detected by Congo red staining and Bielschowsky silver staining. The levels of expression of APP and $\beta$-site APP-cleaving enzyme I (BACE-I) were measured by western blotting and immunohistochemistry.

Results: Ten-month-old Tg mice showed obvious learning-memory impairments, and significant increases in A $\beta$ contents, amyloid plaques, and APP and BACE-I levels in the hippocampus. The intragastric administration of icariin to $\mathrm{Tg}$ mice for 6 months (from 4 to 10 months of age) improved the learning-memory abilities and significantly decreased the $A \beta$ contents, amyloid plaques, and APP and BACE-I levels in the hippocampus.

Conclusion: Icariin reduced the $A \beta$ burden and amyloid plaque deposition in the hippocampus of APP transgenic mice by decreasing the APP and BACE-I levels. These novel findings suggest that icariin may be a promising treatment in patients with $A D$.
\end{abstract}

Key words: Icariin; Alzheimer's disease; APPV717I transgenic mice; $\beta$-amyloid; amyloid plaque; BACE-1; amyloid precursor protein

\section{Introduction}

Alzheimer's disease (AD) is a neurodegenerative disorder that is characterized by the accumulation of amyloid plaques, the formation of neurofibrillary tangles, and selective neuronal death in the brain [1]. The deposition of $\beta$-amyloid (A $\beta)$ is a key pathological event in this disease [2]. It has been identified as a major component of senile plaques in $\mathrm{AD}$ brain, and, thus, it is a major target of therapy for AD. A $\beta$ peptides containing 40 or 42 amino acids are produced by the sequential cleavage of amyloid precursor protein (APP) by $\beta$-secretase and $\gamma$-secretase [3]. $\beta$-Site APP-cleaving enzyme-1 (BACE-1, i.e., $\beta$-secretase) plays a critical role in $A \beta$ production and amyloidosis in the central nervous system, thus, it has been con- 
sidered a high-priority therapeutic target $[4,5]$. Mutations in human APP around $\beta$ - or $\gamma$-secretase cleavage sites have been shown to be associated with early onset familial $A D$, which is characterized by increased levels of $A \beta_{1-42}$ [6]. Consequently, transgenic mice that overexpress human mutant APP at high levels have been widely used in the study of $A D$ pathogenesis or anti-AD drugs.

APP transgenic mice, which exhibit neurodegenerative changes in behavioral, biochemical and histopathological aspects that are similar to those observed in patients with $\mathrm{AD}$, are a valuable animal model for AD prevention and treatment studies [7]. In our previous study, APPV717I transgenic mice that overexpressed neuron-specific transgenes with London mutations (V717I) in human APP exhibited deficits in learning and memory with aging, ultrastructural injuries, and decreased protein expression in synapses [8].

Icariin $\left(\mathrm{C}_{33} \mathrm{H}_{40} \mathrm{O}_{15}\right.$; molecular weight 676.65$)$ is the major active component extracted from the traditional Chinese herb Epimedium [9], and has been reported to have various pharmacological effects, such as cardiac protective effects [10], anti-inflammatory effects [11], and even anti-tumor properties [12]. According to some studies about the pharmacokinetics of icariin, it was proved that icariin could pass through the blood-brain barrier [13, 14]. A few studies showed that icariin improved learning and memory abilities in aged rats or $A \beta_{25-35}$ hippocampal injection rats $[15,16]$, but those models were not the exact $A D$ models. Urano et al. reported that administration of icariin improved spatial memory impairment in transgenic mouse AD model (5xFAD), and attenuated neurite atrophy in an in vitro cell model induced by $\mathrm{A} \beta_{1-42}$ [17], but they did not detect APP, secretases, $A \beta$ and amyloid plaques in vivo. Therefore, it was not clear whether icariin could influence key proteins and enzymes in the $A \beta$ amyloidogenic pathway in an $A D$ transgenic mouse model.

The APPV717I transgenic mice that are bred on a C57/BL6 strain express high levels of human APP751 containing the London (V717I) mutation under the platelet-derived growth factor promoter [18], which results in a marked increase of $A \beta_{1-42}$ production [19]. In the present study, we investigated the pharmacological effects and mechanisms of icariin on key steps of $A \beta$ production and deposition in APPV717I transgenic mouse model of $\mathrm{AD}$.

\section{Materials and methods}

\section{Ethics Statement}

This study was approved by Animal Ethics Committee of Xuanwu Hospital of Capital Medical
University.

\section{Drugs}

Icariin, with a molecular weight of 676.65 $\left(\mathrm{C}_{33} \mathrm{H}_{40} \mathrm{O}_{15}\right)$, was obtained from the National Institute for Food and Drug Control (Beijing, China). Powder of icariin (with 99\% purity as determined by a high-performance liquid chromatography assay) was dissolved in distilled water and intragastrically administered to mice between 8 and 9 AM every day.

\section{Animals and drug administration}

In the present study, 3-month-old APPV717I transgenic ( $\mathrm{Tg}$ ) mice were obtained from the Institute of Experimental Animals of the Chinese Academy of Medical Sciences (Beijing, China). The gene mutation in each mouse has been confirmed by polymerase chain reactions of peripheral blood [20]. Animal housing and all experimental procedures followed the requirements of the Provisions and General Recommendations of Chinese Experimental Animal Administration Legislation. Animals were housed under a 12/12-h dark/light cycle and in standard pathogen-free conditions. They had free access to food and water throughout the entire experiment.

After 4-week acclimatization to their home cage, 4-month-old APPV717I Tg mice were randomly divided into 3 groups: APP Tg, APP $\mathrm{Tg}+$ ICA 30 $\mu \mathrm{mol} / \mathrm{kg}$, and APP Tg + ICA $100 \mu \mathrm{mol} / \mathrm{kg}$. Each group consisted of 18 mice (half female and half male). The same number of transgenic-negative and non-transgenic C57/BL6 littermates served as $\mathrm{Tg}(-)$ controls and normal controls, respectively.

The mice in APP Tg + ICA groups received daily gavages of dissolved icariin $(0.1 \mathrm{~mL} / 10 \mathrm{~g}$ weight $)$ and all mice in other groups were intragastrically administered an equal volume of distilled water once a day for 6 months beginning at 4 months of age.

\section{Behavioral experiments}

Morris water maze (MWM)

This MWM consisted of 4 days of learning-memory training and a probe trial that was applied on day 5 . The animals were trained in a circular pool (120 cm in diameter) that was located in a lit room with visual cues. An escape platform $(9.5 \mathrm{~cm}$ in diameter) was submerged $1.0 \mathrm{~cm}$ below the surface of the pool water, which was maintained at $23 \pm 2{ }^{\circ} \mathrm{C}$ and mixed with milk powder in order to obscure the platform. The location of the platform remained in the center of the northwest quadrant throughout the 4-day training period. On each day, mice were trained in 1 morning and afternoon block. Each block consisted of 2 trials, and each trial lasted for $120 \mathrm{~s}$ or ended as soon as the mice reached the submerged 
platform, thus escaping from the water maze. Before the first trail, each mouse was put on the platform for $15 \mathrm{~s}$, which was followed by a 60-s free swim, and the mouse was then assisted to the platform where it remained for another $15 \mathrm{~s}$ of rest. Then, the test began: the mouse was released into the water facing the pool wall, turning north, south, east, and west for each trial. Whether a mouse found or failed to find the platform within $120 \mathrm{~s}$, it was placed on the platform for $15 \mathrm{~s}$. Data on the escape latencies from the water maze, which was defined as finding the submerged escape platform, and the distances that the mice had traveled were collected, and the swimming speed of each mouse in every single trial was calculated. The probe trial was formed by removing the platform and allowing each mouse to swim freely for $60 \mathrm{~s}$ inside the pool. The swimming time and distance traveled by each mouse in the target quadrant when the platform had been removed were recorded by a computerized video system. The ratio of time and distance in the quadrant to those in the whole pool were calculated and compared among the groups.

\section{Object recognition test (ORT)}

The observation arena, with a size of $45 \mathrm{~cm} \times 35$ $\mathrm{cm} \times 20 \mathrm{~cm}$, was made up of white plastic and was located in a testing room that was dimly lit by constant illumination at about $40 \mathrm{~lx}$ in the testing arena. The objects chosen were 3 identical cuboid blue plastic blocks (A; $4.5 \mathrm{~cm} \times 4.5 \mathrm{~cm} \times 5 \mathrm{~cm})$ and a white cylindrical plastic bottle (B; height: $7 \mathrm{~cm}$; diameter: $4 \mathrm{~cm}$ ) that was filled with water. These objects were heavy enough to prevent the mice from moving them. According to our screening test, these 2 kinds of objects elicited roughly the same exploratory time relative to the other. Two identical sets of arenas and objects were used by 2 observers who conducted the tests independently in the same room but who were hidden from each other. Each person randomly tested half of the mice in each group. The test lasted for 3 days. On day 1 , the mice were placed in the arena for $10 \mathrm{~min}$ in order to reduce neophobic responses and habituate the animals to the stimuli that were presented in the empty arena. On day 2, 2 identical objects (A1A2 or B1B2) were placed at opposite sides in each arena $8 \mathrm{~cm}$ from the walls and with $29 \mathrm{~cm}$ between them. The mice were placed in the middle of the space between the objects in order to start a 10-min period of object learning and training. On day 3, 1 familiar (previously observed) object and 1 new object were placed in the arena (A3B or B3A for each arena), and the mice were placed in the middle of the space between the objects to start a 10-min object recognition test. Object exploration was defined as the exhibition of the orientation in which the animal's snout was moved towards the object and the mouse was located within $2 \mathrm{~cm}$ or less of the object. Incidents of the mouse running around the object or sitting on it were not recorded as an exploratory behavior. Objects were washed with ethanol after each individual trial in order to equate olfactory cues. The time spent exploring the familiar object and the new object during days 2 and 3 was observed visually and timed with stopwatches. The objects' positions (at the sides of the arena) were alternated for each animal in order to reduce errors in our collected data. The times when the mice exhibited exploratory behaviors were recorded and used to calculate a memory discrimination index (DI), as previously reported [21]. DI $=(\mathrm{N}-$ $\mathrm{F}) /(\mathrm{N}+\mathrm{F})$, where $\mathrm{N}$ is the time spent exploring the new object and $\mathrm{F}$ is the time spent exploring the familiar object. Higher DI was considered a reflection of greater memory ability.

\section{Western Blotting}

For the western blotting assay, we used anti-APP, anti-BACE-1, and anti-PS-1 antibodies from Sigma-Aldrich Co. LLC (St. Louis, MO, USA). The hippocampi from 5 individual mice in each group were homogenized in iced buffer containing $50 \mathrm{mM}$ Tris- $\mathrm{HCl}$ ( $\mathrm{pH}$ 7.5), $1 \mathrm{mM}$ ethylenediaminetetraacetic acid, $0.5 \mathrm{mM}$ ethylene glycol tetraacetic acid, $150 \mathrm{mM}$ $\mathrm{NaCl}$, and $1 \%$ protease inhibitor cocktail (Sigma-Aldrich Co. LLC). A western blot analysis was performed as described previously [22]. Proteins were separated by sodium dodecyl sulfate (SDS)-polyacrylamide gel electrophoresis, blotted onto a polyvinylidene fluoride membrane, and reacted with the primary antibody. A horseradish peroxidase-conjugated goat-anti-mouse IgG $(1: 5,000)$ was used as a secondary antibody. Immunoreactive bands were visualized by enhanced chemiluminescence (ECL system; Santa Cruz Biotechnology, Inc., Santa Cruz, CA, USA) and exposed to x-ray film (Kodak, Rochester, NY, USA).

\section{Immunohistochemistry}

For the immunohistochemical staining, we used anti-A $\beta$, anti-APP, anti-BACE-1, and anti-PS-1 monoclonal antibodies (Sigma-Aldrich Co. LLC). Five mice in each group were sacrificed and immediately perfused through the heart with $0.9 \% \mathrm{NaCl}$, which was followed by $4 \%$ paraformaldehyde in $0.1 \mathrm{M}$ phosphate buffer for $10 \mathrm{~min}$. Brains were postfixed by immersion for 4 days and then cryoprotected in $20 \%$ sucrose. Brains were rapidly frozen in OCT embedding medium, and frozen sections with a thickness of $20 \mu \mathrm{m}$ were taken through the hippocampus and processed in free-floating conditions. Immunohistochemical procedures for light microscopic examina- 
tions were performed as described previously [22] with slight modifications. Sections were treated with $0.1 \mathrm{M}$ phosphate-buffered saline containing $0.3 \%$ Triton X-100 (PBST) for 4 days and first incubated with the primary antibody overnight at $4^{\circ} \mathrm{C}$. The sections were then incubated with the second biotinylated goat anti-mouse IgG antibody $(1: 1,000)$ at room temperature for $2 \mathrm{~h}$ and finally with horseradish-conjugated streptavidin $(1: 1,000)$ at room temperature for $1 \mathrm{~h}$. Peroxidase activity was revealed by $0.02 \% 3,3^{\prime}$-diaminobenzidine in $0.05 \mathrm{M}$ Tris- $\mathrm{HCl}$ buffer, $\mathrm{pH} 7.6$, containing $0.005 \% \mathrm{H}_{2} \mathrm{O}_{2}$ and $0.3 \%$ nickel ammonium sulfate. The stained sections were mounted on glass slides, dehydrated, cleared, and coverslipped. The quantitative analysis of the $A \beta$ burden was expressed as the percent area of $A \beta$ deposits in the whole brain tissue area that was examined.

\section{Congo red staining and Bielschowsky silver staining}

\section{Congo red staining}

Three slides from each mouse were rehydrated in graded alcohols, immersed in Hematoxylin for 2 $\mathrm{min}$, and then dipped in hydrochloric alcohol for $10 \mathrm{~s}$. Firstly, sections were rinsed in running tap water until it turned blue and distilled water 2 times. Then, sections were Congo red stained for $40 \mathrm{~min}$ at room temperature before being rinsed in running water; they were then dipped in lithium carbonate for $5 \mathrm{~s}$ and washed in running tap water. Alcohol $(80 \%)$ was used to differentiate the nonspecific background staining, and the sections were then rinsed in running tap water for $10 \mathrm{~min}$, cleared in xylene, and covered with neutral gum.

\section{Bielschowsky silver staining}

Three slides from each mouse were rehydrated in graded alcohols before being rinsed in distilled water 3 times. They were then immersed in $2-4 \%$ argent nitrate solution for $25-35 \mathrm{~min}$ at $37^{\circ} \mathrm{C}$ in the dark. The slides were washed in distilled water 3 times after the argent nitrate solution was removed. The staining was deoxidized with $10 \%$ formaldehyde until the slide changed to a pale-yellow color. The slides were rinsed in distilled water 3 times, and the excess water was removed. Ammoniacal silver solution $(200 \mu \mathrm{L})$ was added to each slide for $5 \mathrm{~min}$. The excess solution was removed, and the slides were dipped in $8 \%$ formalin for $2 \mathrm{~min}$. Slides were rotated several times until the yellow dye remained stable. The sections were fixed in $5 \%$ sodium thiosulfate for $5 \mathrm{~min}$. Slides were dried in the open air, cleared in xylene, and then coverslipped for the microscopic examinations.

\section{A $\beta$ measurements of the brain tissue by enzyme-linked immunosorbent assay (ELISA)}

With highly specific antibodies and a sensitive sandwich ELISA, we quantified $A \beta_{1-42}$ in brain homogenate fractions that were extracted with TBS (50 $\mathrm{mM}$ Tris- $\mathrm{HCl}, \mathrm{pH} 7.6,150 \mathrm{mM} \mathrm{NaCl}$ ) or $2 \%$ SDS and $70 \%$ formic acid, respectively, as described previously. Frozen hippocampal samples were homogenized with a homogenizer in $1 \mathrm{~mL}$ of TBS/complete protease inhibitor plus $20 \mu \mathrm{g} / \mathrm{mL}$ pepstatin A (Roche Diagnostics $\mathrm{GmbH}$, Mannheim, Germany) and then centrifuged at $100,000 \times g$ for $1 \mathrm{~h}$ at $4^{\circ} \mathrm{C}$ with an $\mathrm{Op}$ tima TLX ultracentrifuge (Beckman Coulter, Inc., Brea, CA, USA). The TBS supernatants were stored at $-80^{\circ} \mathrm{C}$, and the pellets were homogenized in $1 \mathrm{~mL}$ of $2 \%$ SDS/TBS with protease inhibitor (Roche Diagnostics $\mathrm{GmbH}$ ). They were then centrifuged at 100,000 $\times g$ for $1 \mathrm{~h}$ at $25^{\circ} \mathrm{C}$ following incubation for $15 \mathrm{~min}$ at $37^{\circ} \mathrm{C}$. The pellets, which corresponded to the insoluble fraction, were washed once and then extracted further with $1 \mathrm{~mL}$ of $70 \%$ formic acid. They were then centrifuged at $100,000 \times g$ for $1 \mathrm{~h}$. The supernatants of insoluble $70 \%$ formic acid extracts were neutralized with $1 \mathrm{M}$ Tris- $\mathrm{HCl}(\mathrm{pH} 8.0)$ at a dilution of 1:20. For quantification of $A \beta_{1-42}$, we used an specific ELISA Kit (\#27711, recognizing human $A \beta_{1-42}$ and the cross reactivity with mouse $A \beta_{1-42}$ was $70.9 \%$, Immuno-Biological Laboratories Co., Ltd., Gunma, Japan) according to the manufacturer's instructions.

\section{Statistical analysis}

All data were expressed as mean \pm standard deviation (SD). The differences among the groups were analyzed with one-way analysis of variance (ANOVA) followed by the Post-hoc Duncan multiple group comparison. $P$ values less than 0.05 were considered statistically significant.

\section{Results}

\section{Effects of icariin on learning and memory impairments in APP transgenic mice}

In the present study, the Morris water maze was used to examine the spatial learning and memory performances of mice. Escape latency in first training trial among groups varied from $89.94 \mathrm{~s}$ to $97.18 \mathrm{~s}$, indicating no significant difference among groups. "Escape latency" in Figure 1 is the data in the last trial after 4 day's training. Both the 4- and 10-month-old $\mathrm{Tg}(+)$ mice showed significantly prolonged escape latencies compared with the age-matched transgenic-negative $[\mathrm{Tg}(-)]$ control group $(P<0.05, P<0.01)$. The escape latencies of 10 -month-old $\mathrm{Tg}(+)$ mice were significantly longer than those of 4-month-old $\mathrm{Tg}(+)$ mice $(P<0.01)$, while no significant differences were 
found between the normal control group and the age-matched $\mathrm{Tg}(-)$ group (Fig. 1A). However, the 10-month-old $\mathrm{Tg}(+)$ mice that had been intragastrically treated with icariin $(100 \mu \mathrm{mol} / \mathrm{kg})$ for 6 months beginning at 4 months of age showed significantly shorter escape latencies than vehicle-treated 10 -month-old $\mathrm{Tg}(+)$ mice $(P<0.01$; Fig. $1 \mathrm{~B})$.

In the probe trials of the Morris water maze, mice were allowed to search the platform for $60 \mathrm{~s}$ in an empty maze. Fig. 1C illustrates group differences of the mean percentage searching time in the target quadrant compared to the whole pool during the probe trial. Compared with age-matched $\operatorname{Tg}(-)$ group, $\operatorname{Tg}(+)$ mice at both 4 months and 10 months of age showed a significant less time in the target quadrant $(P<0.05, P<0.01)$. The time in the target quadrant showed a significantly decrease in 10-month-old $\mathrm{Tg}(+)$ mice compared with those in 4-month-old $\mathrm{Tg}(+)$ mice $(P<0.05)$, while no significant differences were found between the normal control group and the age-matched $\mathrm{Tg}(-)$ group (Fig. 1C). The 10-month-old $\operatorname{Tg}(+)$ mice that had been treated with icariin $(100$ umol $/ \mathrm{kg}$ ) for 6 months beginning at 4 months of age showed significantly longer time in the target quadrant than vehicle-treated 10 -month-old $\mathrm{Tg}(+)$ mice $(P<0.01$; Fig. 1D).

In the object recognition test (ORT), there was no significant difference in the exploration time to 2 identical objects on day 2 among groups (data not shown). On day 3, 10-month-old $\mathrm{Tg}(+)$ mice showed a significant decrease in the memory discrimination index (DI) compared with both age-matched $\operatorname{Tg}(-)$ mice $(P<0.05)$ and 4-month-old $\operatorname{Tg}(+)$ mice $(P<0.01$; Fig. 2A). The DI was significantly increased in mice that were treated with icariin $(100 \mu \mathrm{mol} / \mathrm{kg})$ for 6 months compared with the $\mathrm{Tg}(+)$ model mice $(P<0.05)$, suggesting an improvement in object recognition memory by icariin treatment (Fig. 2B). There was no significant difference in total exploration time $(\mathrm{N}+\mathrm{F})$ that was observed among groups.

These results provided evidence that icariin ameliorated the learning and memory deficits of $\operatorname{Tg}(+)$ mice.

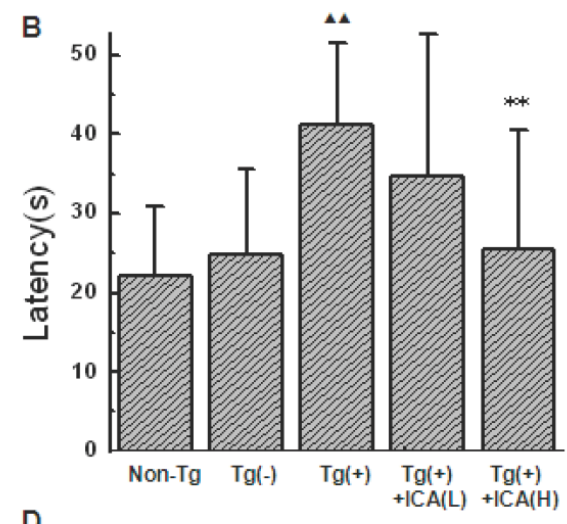

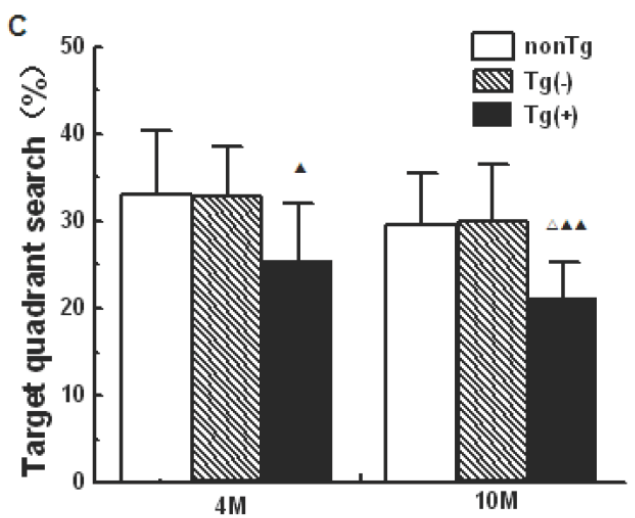
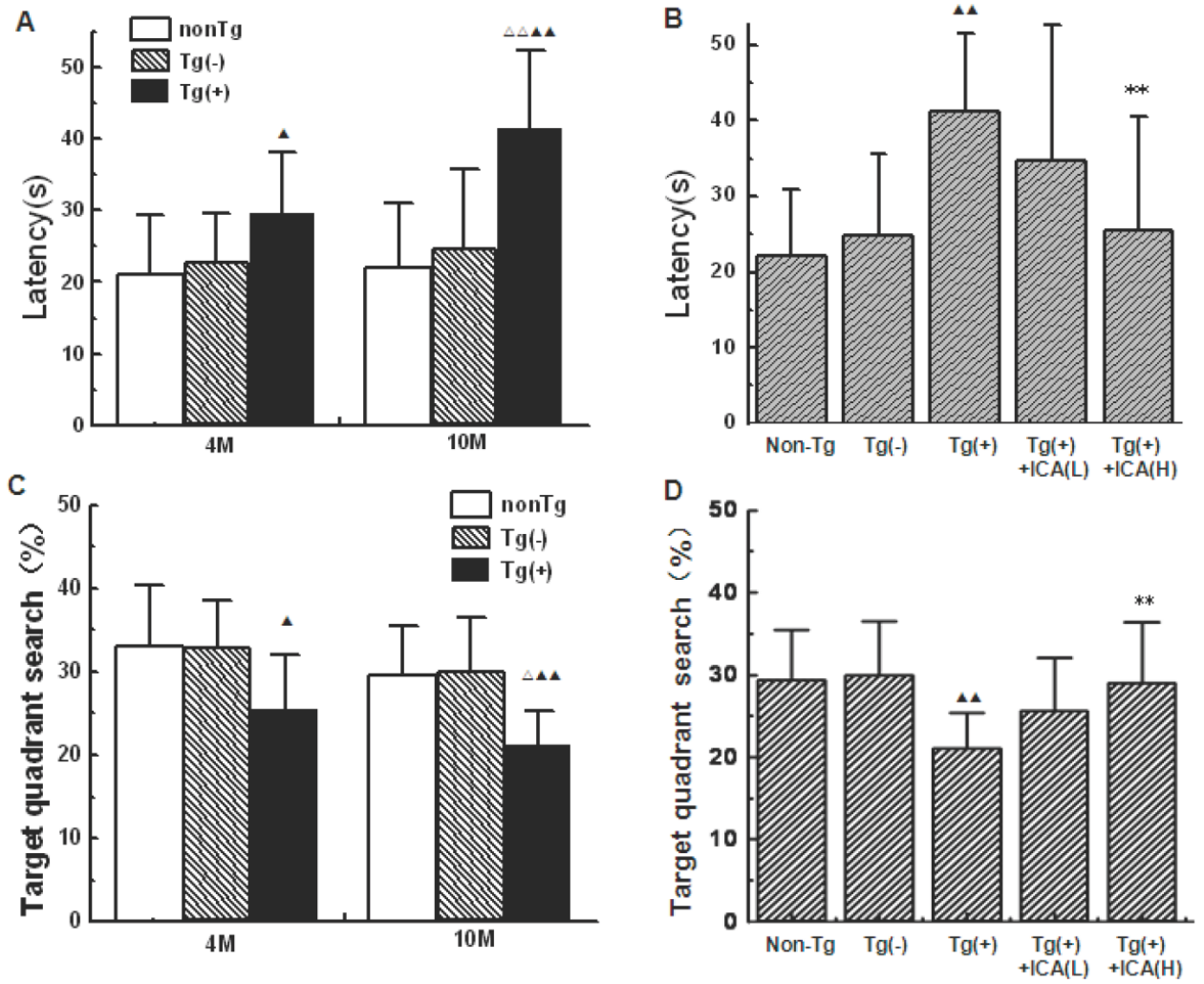

Fig. I. Effects of icariin on learning and memory impairments in APP V7 I 7I transgenic mice (Morris water maze). Icariin (ICA) at the doses of $30 \mu \mathrm{mol} / \mathrm{kg}(\mathrm{L})$ and $100 \mu \mathrm{mol} / \mathrm{kg}(\mathrm{H})$ was intragastrically administered to APP Tg mice for 6 months (from 4 to 10 months of age). "Escape latency" is the data in the last trial after 4 day's training. A. Comparison of escape latencies in different mice groups at 4 months of age and 10 months of age. B. Effects of icariin on escape latencies in 10-month-old APP transgenic $(\mathrm{Tg})$ mice. C. Group differences of the mean percentage searching time in the target quadrant compared to the whole pool during the probe trial. D. Effects of icariin on the time in the target quadrant. $n=18$. The data are shown as mean \pm standard deviation (SD); ${ }^{\Delta} P<0.05,{ }^{\Delta}{ }_{P}<0.01$, compared with transgenic-negative [Tg(-)] mice; $\triangle \triangle P<0.01$, compared with 4-month-old APP Tg mice; $* * P<0.0$ I, compared with APP $\operatorname{Tg}(+)$ model mice. 
A

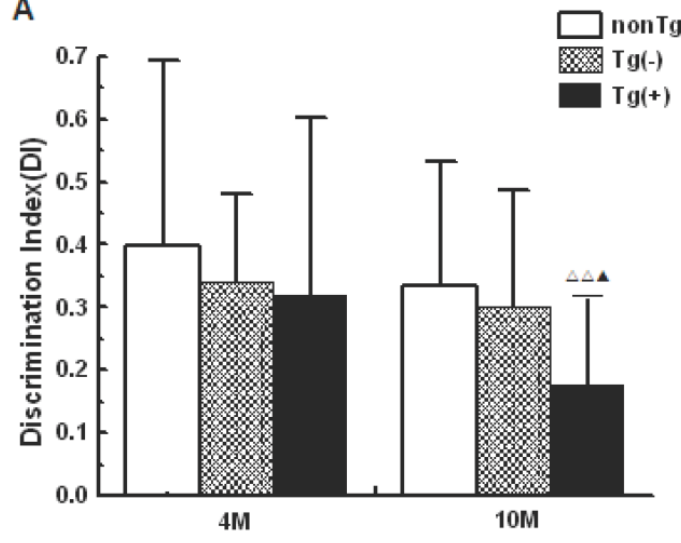

B

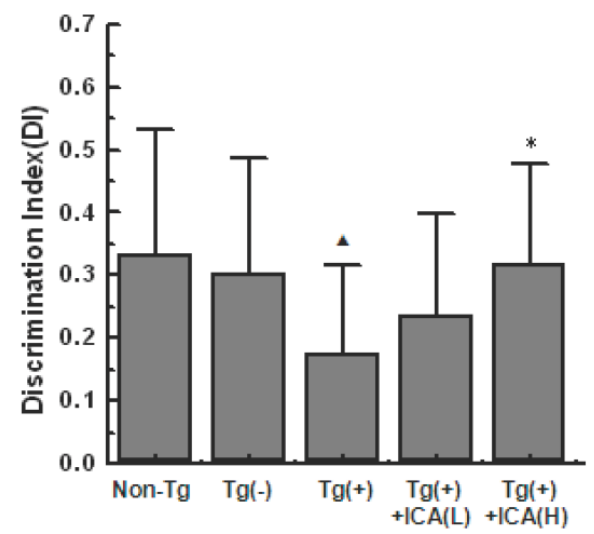

Fig. 2. Effects of icariin on learning and memory impairments in APP V7 I 7I transgenic mice (object recognition test, ORT). Icariin (ICA) at the doses of $30 \mu \mathrm{mol} / \mathrm{kg}(\mathrm{L})$ and $100 \mu \mathrm{mol} / \mathrm{kg}(\mathrm{H})$ was intragastrically administered to APP Tg mice for 6 months (from 4 to 10 months of age). A. Comparison of the discrimination index (DI) in different mice groups at 4 months of age and 10 months of age. B. Effects of icariin on DI in $10-$ month-old APP Tg mice. On day 2, there was no significant difference in the exploration time to 2 identical objects among groups. On day 3 , there was no significant difference in total exploration time (N+F) among groups. $n=18$. The data are shown as mean $\pm \mathrm{SD} ;{ }^{\mathbf{\Delta}} P<0.05$, compared with $\mathrm{Tg}(-)$ mice; $\triangle \Delta P<0.0 \mathrm{I}$, compared with 4-month-old APP Tg mice; ${ }^{*} P<0.05$, compared with APP $\mathrm{Tg}(+)$ model mice.

A
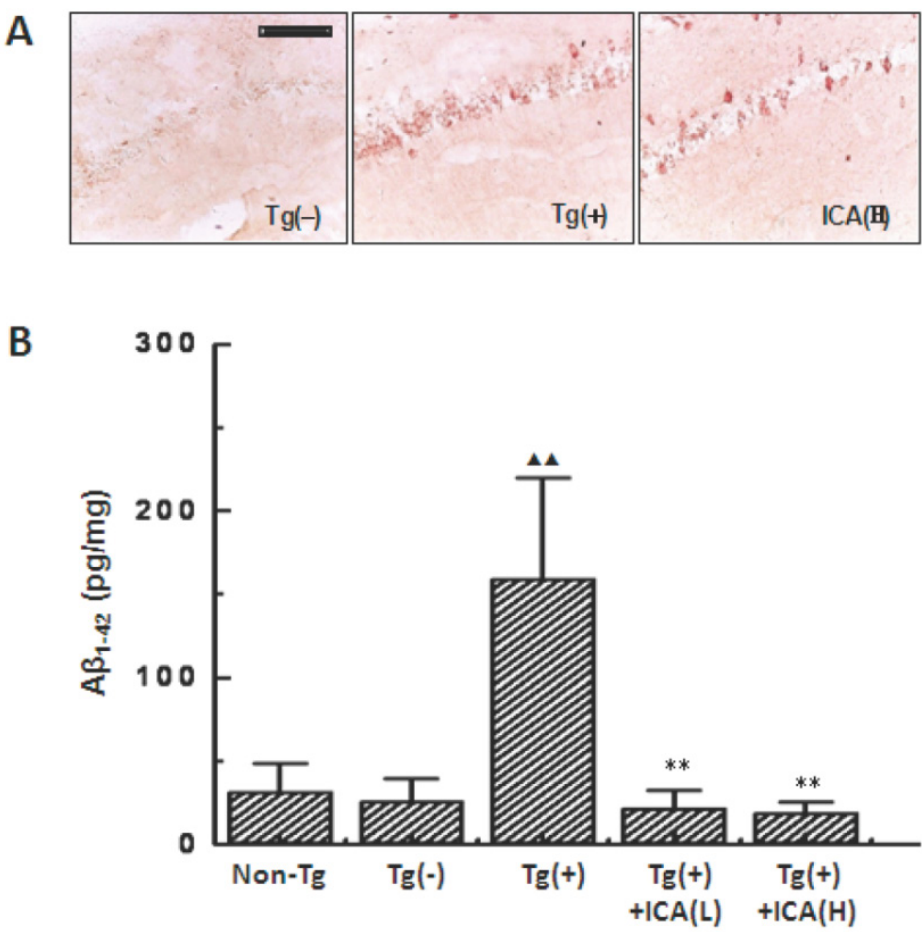

Fig. 3. Effects of icariin on $\mathbf{A} \boldsymbol{\beta}$ contents in the hippocampus of 10 -month-old APP V7I7I transgenic mice. Icariin (ICA) at the doses of 30 $\mu \mathrm{mol} / \mathrm{kg}(\mathrm{L})$ and $100 \mu \mathrm{mol} / \mathrm{kg}(\mathrm{H})$ was intragastrically administered to APP Tg mice for 6 months (from 4 to 10 months of age). A. A burden in the hippocampal CAI region that was detected with immunohistochemical staining by using anti-A $\beta|-| 6$ antibody (scale bar $=50 \mu \mathrm{m}$ ). $n=5$. B. A $\mathrm{A} I-42$ contents in the whole hippocampus that were measured with enzyme-linked immunosorbent assays. $n=8-10$. The data are shown as mean \pm SD; ${ }^{\mathbf{\Lambda}} P<0.0$, compared with $\mathrm{Tg}(-)$ mice; ** $P<0.0 \mathrm{I}$, compared with $\mathrm{Tg}(+)$ model mice.

\section{Effects of icariin on $A \beta$ content in the hippocampus of APP transgenic mice}

The immunohistochemical staining with the anti- $A \beta_{1-16}$ was used to evaluate the total $A \beta$ burden in mouse brain. The number of $A \beta$-positive cells was significantly increased in the hippocampal CA1 region of $\mathrm{Tg}(+)$ mice at the age of 10 months compared with that in the age-matched $\mathrm{Tg}(-)$ control group.
$\mathrm{Tg}(+)$ mice that were treated with $100 \mu \mathrm{mol} / \mathrm{kg}$ icariin showed an obvious decrease in the number of $\mathrm{A} \beta$-positive cells compared with that in the $\mathrm{Tg}(+)$ model mice (Fig. 3A).

Since anti-A $\beta_{1-16}$ antibody cannot distinguish between $A \beta_{1-40}$ and $A \beta_{1-42}$, and $A \beta_{1-42}$ is more cytotoxic and more likely to aggregate to form plaques than $A \beta_{1-40}$, we further examined $A \beta_{1-42}$ with ELISA. As a result, the levels of $A \beta_{1-42}$ were found to be sig- 
nificantly increased in the hippocampus of $\mathrm{Tg}(+)$ mice at the age of 10 months compared to the age-matched $\mathrm{Tg}(-)$ control group $(P<0.01)$. These increased levels were decreased by treatment with 30 and 100 $\mu \mathrm{mol} / \mathrm{kg}$ icariin for 6 months (from 4 to 10 months of age) compared to those in the $\mathrm{Tg}(+)$ model mice $(P<0.01)$ (Fig. 3B).

\section{Effects of icariin on amyloid plaques in the hippocampus of APP transgenic mice}

Congo red was used to stain the amyloid plaques in the brains of mice, and the positively stained areas were measured with an image analysis system in order to determine the quantity of amyloid plaques. The results showed that amyloid plaques were scattered in the molecular/polymorphic layer of the hippocampus, and rare amyloid plaques were distributed in the pyramidal cell layer. The amyloid plaques exhibited a light red dispersion without distinct boundaries, and plaque staining was denser in the hippocampus of $\operatorname{Tg}(+)$ mice (Fig. 4A). The molecular layer in the hippocampi of 10-month-old $\mathrm{Tg}(+)$ mice had a larger percentage of areas that were positive for amyloid plaques than the age-matched $\operatorname{Tg}(-)$ control group $(P<0.01)$. After icariin $(30$ and $100 \mu \mathrm{mol} / \mathrm{kg})$ administration for 6 months, the plaque staining was lighter, and the positively stained areas of amyloid plaques were significantly reduced $(P<0.01)$ (Fig. 4B).

The results from the Bielschowsky silver staining also showed that amyloid plaques were mainly scattered in the hippocampal molecular layer, and these results were consistent with the results from the Congo red staining. Mature amyloid plaques exhibited round, oval, or irregular shapes, deeply dyed cores, and shallow surrounding halos at high magnification. Diffuse plaques appeared as loose reticular spheres with light coloring and without a deeply dyed and dense core. The number of amyloid plaques was increased in the hippocampal molecular layer, and dominantly mature amyloid plaques were dense and deeply dyed in $\operatorname{Tg}(+)$ mice at the age of 10 months, while age-matched $\operatorname{Tg}(-)$ mice exhibited no plaques in the hippocampus. The amyloid plaques in these brain regions in 30 and $100 \mu \mathrm{mol} / \mathrm{kg}$ icariin-treated $\mathrm{Tg}(+)$ mice appeared diffusely and lightly stained, and the number of plaques was reduced compared with that in the age-matched $\mathrm{Tg}(+)$ model group (Fig. $4 \mathrm{C}$ ).
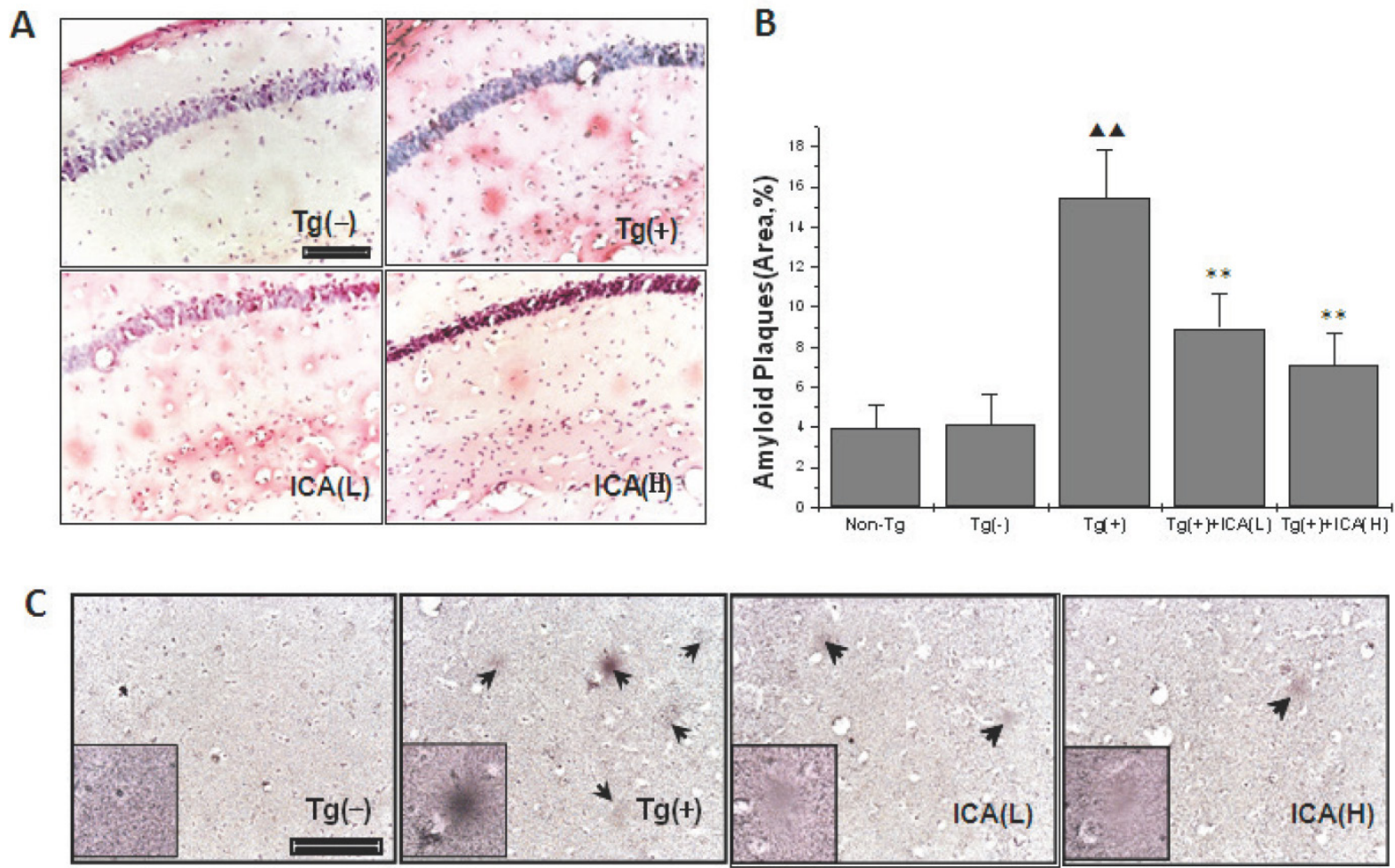

Fig. 4. Effects of icariin on amyloid plaques in the hippocampus of 10 -month-old APP V7I 7 I transgenic mice. Icariin (ICA) at the doses of $30 \mu \mathrm{mol} / \mathrm{kg}(\mathrm{L})$ and $100 \mu \mathrm{mol} / \mathrm{kg}(\mathrm{H})$ was intragastrically administered to APP Tg mice for 6 months (from 4 to 10 months of age). A. Congo red staining. B. Semiquantitative analysis of Congo red staining. C. Bielschowsky silver staining. $n=5$. The data are shown as mean $\pm S D ;{ }^{\mathbf{\Lambda}} P<0.01, c o m p a r e d$ with $\mathrm{Tg}(-)$ mice; $* * P<0.01$, compared with $\operatorname{APP} \operatorname{Tg}(+)$ model mice. Scale bar $=50 \mu \mathrm{m}$. 


\section{Effects of icariin on APP expression in the hippocampus of APP transgenic mice}

The levels of APP that were detected by western blot were significantly increased in the $\operatorname{Tg}(+)$ mice compared with those in the age-matched $\operatorname{Tg}(-)$ control group $(P<0.05)$. After icariin administration at doses of 30 and $100 \mu \mathrm{mol} / \mathrm{kg}$ for 6 months, the levels of APP expression were obviously reduced compared with those in the $\operatorname{Tg}(+)$ model group $(P<0.05, P<0.01)$ (Fig. $5 \mathrm{~A}$ and $\mathrm{B})$. The 6-month treatment of $100 \mu \mathrm{mol} / \mathrm{kg}$ icariin did not show the significant change in APP expression in normal C57/BL6 mice (data not shown).

APP expression was also observed in hippocampal CA1 areas with immunohistochemical staining. The N-terminal of APP-positive markers presented as brown granules, which were mainly distributed in the hippocampal neuronal cytoplasm when observed under the light microscope. Compared with the $\operatorname{Tg}(-)$ control group, APP-positive cells were significantly increased with deep staining in the cytoplasm in the hippocampal CA1 areas of 10 -month-old $\mathrm{Tg}(+)$ mice. The $100 \mu \mathrm{mol} / \mathrm{kg}$ icariin-treated group showed less APP-positive cells in the hippocampal CA1 regions compared with those in $\mathrm{Tg}(+)$ model mice (Fig. 5C).
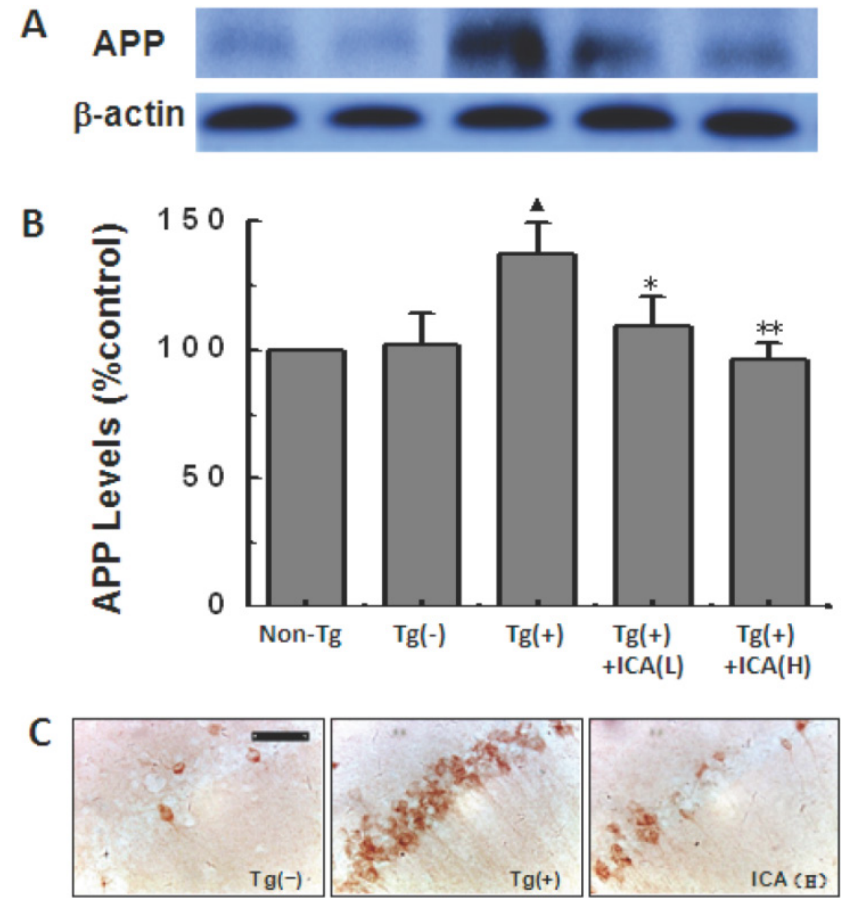

Fig. 5. Effects of icariin on amyloid precursor protein (APP) expression in the hippocampus of 10-month-old APP V7I7I transgenic mice. Icariin (ICA) at the doses of $30 \mu \mathrm{mol} / \mathrm{kg}(\mathrm{L})$ and 100 $\mu \mathrm{mol} / \mathrm{kg}(\mathrm{H})$ was intragastrically administered to APP Tg mice for 6 months (from 4 to 10 months of age). A. Western blot. B. Semiquantitative analysis of western blot. C. Immunohistochemical staining (scale bar $=50 \mu \mathrm{m}) . n=5$. The data are shown as mean \pm SD; ${ }^{\mathbf{\Lambda}} P<0.05$, compared with $\mathrm{Tg}(-)$ mice; $* P<0.05, * * P<0.01$, compared with $\mathrm{Tg}(+)$ model mice.
Effects of icariin on BACE-I expression in the hippocampus of APP transgenic mice

The levels of expression of BACE-1 ( $\beta$-secretase) in the hippocampus of 10-month-old mice were detected by western blotting. The results indicated significantly higher levels of expression of BACE-1 in $\operatorname{Tg}(+)$ mice compared with those in the $\operatorname{Tg}(-)$ control group $(P<0.01)$. The high levels of BACE-1 expression in $\operatorname{Tg}(+)$ mice were significantly reduced by icariin administration at a dose of $100 \mu \mathrm{mol} / \mathrm{kg}$ for 6 months $(P<0.05)$ (Fig. 6A and B).

BACE-1 expression was also observed in the mouse hippocampal CA1 area with immunohistochemical staining. Brown granules, which represented positive BACE-1 immunohistochemical staining, were seen in the neuronal cytoplasm with light microscopy. Compared to the $\mathrm{Tg}(-)$ control group, BACE-1-positive cells were significantly increased and they exhibited dense staining in the cytoplasm in hippocampal CA1 in 10-month-old $\mathrm{Tg}(+)$ mice. The $100 \mu \mathrm{mol} / \mathrm{kg}$ icariin-treated $\mathrm{Tg}(+)$ group had less BACE-1-positive cells in the hippocampal CA1 region compared with that in the $\mathrm{Tg}(+)$ model group (Fig. $6 C)$.
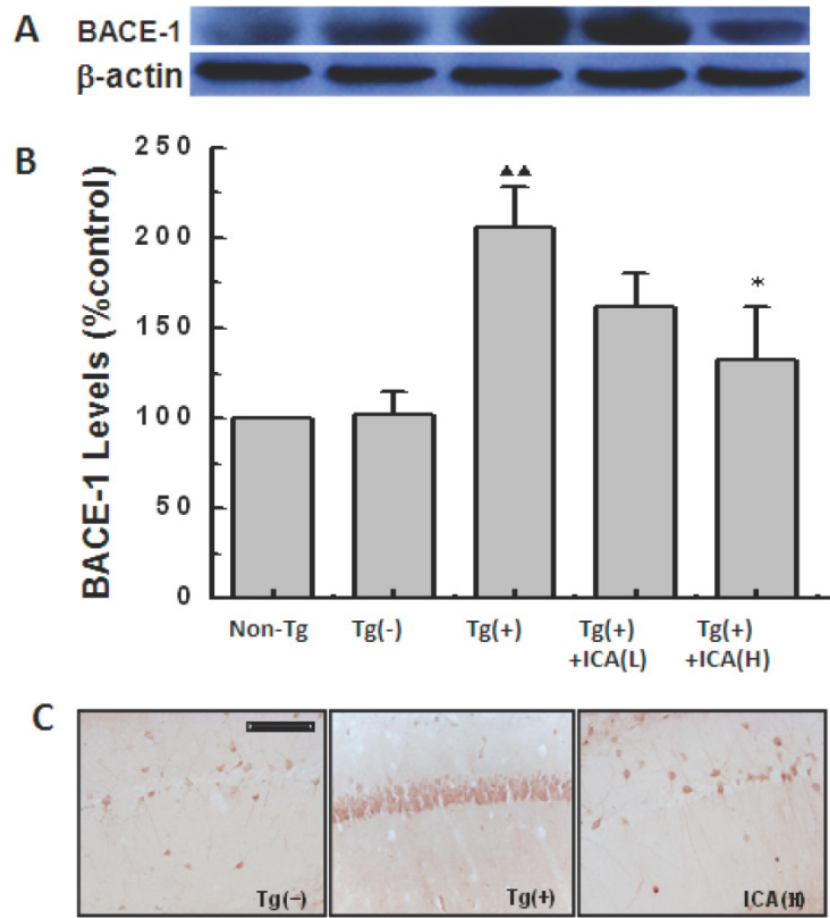

Fig. 6. Effects of icariin on $\beta$-site APP-cleaving enzyme I (BACE-I) expression in the hippocampus of 10 -month-old APP V7 I 71 transgenic mice. Icariin (ICA) at the doses of $30 \mu \mathrm{mol} / \mathrm{kg}$ (L) and $100 \mu \mathrm{mol} / \mathrm{kg}(\mathrm{H})$ was intragastrically administered to APP Tg mice for 6 months (from 4 to 10 months of age). A. Western blot. B. Semiquantitative analysis of western blot. C. Immunohistochemical staining (scale bar $=50$ $\mu \mathrm{m}) . n=5$. The data are shown as mean $\pm \mathrm{SD}$; ${ }^{\mathbf{\Delta}}{ }_{P<0.01}$, compared with $\mathrm{Tg}(-)$ mice; $* P<0.05$, compared with $\mathrm{Tg}(+)$ model mice. 


\section{Discussion}

Transgenic mouse models with mutant APP have been widely used both for investigating the mechanisms of $\mathrm{AD}$ and for evaluating the effects of drugs. APP V717I (valine changed into isoleucine)-mutant mice that over-express human APP with a mutant in amino acid 717 have been reported to be a highly valuable model of amyloid pathology [23]. In the present study, we confirmed that APPV717I transgenic mice exhibited impairments in learning-memory abilities as early as 4 months, and these were exacerbated in 10-month-old $\mathrm{Tg}$ mice. The intragastric administration of icariin for 6 months significantly shortened the escape latencies in the Morris water maze test and obviously increased the discrimination index in the object recognition test in $\mathrm{Tg}(+)$ mice at the age of 10 months. Icariin improved the learning-memory deficits in the AD animal model, suggesting that icariin may have the potential to treat $\mathrm{AD}$ patients and ameliorate their cognitive impairment symptoms.

Amyloid plaques are one of the characteristic pathologic hallmarks of $\mathrm{AD}$, and the deposition of $\mathrm{A} \beta$ is the main cause of plaque production. In order to examine the beneficial effects of icariin therapy in AD, we investigated the amyloid plaques and $A \beta$ burden in the brain of APP Tg mice. The results exhibited a significant increase in amyloid plaques and $A \beta$ burden in the hippocampus of 10-month-old APP $\mathrm{Tg}(+)$ mice, which was consistent with other reports [23, 24]. Administration of icariin to the $\operatorname{Tg}(+)$ mice obviously decreased amyloid plaques and $A \beta$ burden. Since $A \beta_{1-42}$ is more cytotoxic and more likely to aggregate to form plaques than $A \beta_{1-40}$ [25], we further examined $A \beta_{1-42}$ with ELISA in our study. At the age of 10 months, the levels of $A \beta_{1-42}$ in the hippocampus were significantly higher in $\operatorname{Tg}(+)$ mice than those in $\operatorname{Tg}(-)$ control mice. There were no significant differences between APP $\mathrm{Tg}(-)$ mice and non-Tg normal mice in the overall data of the entire study. Therefore, it could be inferred that the transgenic operation did not affect the results. Icariin-treated $\operatorname{Tg}(+)$ mice showed a significant reduction in the contents of $A \beta_{1-42}$ in the hippocampus compared with those in age-matched $\operatorname{Tg}(+)$ mice. The treatment of icariin could reduce $A \beta_{1-42}$ in $\operatorname{Tg}(+)$ mice close to $\mathrm{Tg}(-)$ mice $A \beta_{1-42}$ levels, whereas, the levels of amyloid staining in high-dose treated $\mathrm{Tg}(+)$ mice in the immunohistochemistry (IHC) slices were higher than that in $\mathrm{Tg}(-)$ mice. This may be because anti-A $\beta_{1-16}$ monoclonal antibody which we used in IHC staining cannot distinguish between $A \beta_{1-40}$ and $A \beta_{1-42}$, thus the result in IHC staining may represent the total $A \beta$ burden. These results suggest that icariin may mainly reduce $A \beta_{1-42}$ rather than $A \beta_{1-40}$. A down-regulation of $A \beta_{1-42}$ would be an important beneficial effect of icariin as it would inhibit the formation of amyloid plaques and therefore improve the cognitive impairments in APP $\mathrm{Tg}(+)$ mice.

$A \beta$ is generated from APP through sequential cleavage by $\beta$ - and $\gamma$-secretase. $\beta$-Secretase $(\beta$-site amyloid precursor protein-cleaving enzyme 1 , BACE-1) cleaves the ectodomain of APP and generates an APP C-terminal fragment. Then, $\gamma$-secretase cleaves the transmembrane domain and releases $A \beta$ peptides $\left(A \beta_{1-40}\right.$ or $\left.A \beta_{1-42}\right)$ [26]. Thus, APP, BACE-1, and $\gamma$-secretase are all related to $A \beta$ production. In order to elucidate the pharmacological mechanisms by which icariin decreased $A \beta$ content, we examined the expression of these key proteins and enzymes in Tg mice.

As the initiation of $A \beta$ generation, APP is the primary target in the pathological mechanisms in $\mathrm{Tg}$ mouse. In 2- or 4-month-old APPV717I Tg mouse, human APP protein is expressed more than 2-times the endogenic APP level [25]. In the present study, the western blotting and immunohistochemical results showed a tendency for increased APP expression at 4 months of age in the hippocampus of $\mathrm{Tg}$ mice (data not shown). At the age of 10 months, the expression of APP was significantly increased in the hippocampus of Tg mice. APP levels in the hippocampus at the age of 10 months were obviously higher than those at the age of 4 months, which was consistent with other reports [23]. This indicated that the increased expression of APP which was observed with aging might have been due to the initiation of AD pathology in APP Tg mice. In the present study, we found that 6 months of icariin treatment reduced the level of APP expression in the hippocampus of APP V717I Tg mice at the age of 10 months. Since APP is the precursor protein of $A \beta$, excessive APP may increase $A \beta$ production. The inhibitory effect of icariin on the excessive APP expression may be one of the mechanisms by which icariin treatment decreases the $A \beta$ content in the brain of APP Tg mice. The mechanism of icariin to inhibit the over-expression of APP is not clear. Similar with our result of icariin, cerebrolysin treatment significantly reduced the levels of Full-length APP in APP $\mathrm{Tg}$ mice [27]. NeuroAiD®, also known as MLC601, obviously decreased full-length APP levels in APP transfected SH-SY5Y cells [28]. In these reports, the authors did not explain the underlying mechanism of altered APP levels.

Full-length APP has been implicated in several neuronal functions such as cell adhesion, neuronal differentiation, neuronal migration, neurite outgrowth and synapse formation [29]. In our present study, there was no significant change of full-length APP in the brain of normal C57/BL6 mice with 6-month treatment of $100 \mu \mathrm{mol} / \mathrm{kg}$ icariin (data not 
shown). Some studies in other laboratories also proved that there was no significant alteration of neuron morphology and $A \beta_{1-40}$ staining in the brain after 3-month treatment of icariin to normal or sham control rats [30, 31].

The transmembrane protein BACE-1 ( $\beta$-site APP-cleaving enzyme 1 ) is the main $\beta$-secretase that is involved in the $A \beta$-generating process. Previous studies reported an upregulation of neuronal BACE-1 levels in the brains of 3-month-old APPV717I transgenic mice [32], and BACE-1 expression in frontal cortices with $A \beta$ deposition was 3 times as much as in the cerebellum without $A \beta$ burden [33]. In order to determine the pharmacological target of icariin, the levels of expression of BACE- 1 in the brain of APP Tg mice were measured in the present study. BACE-1 expression in the hippocampus showed a mild increase in APPV717I mice at 4 months of age (data not shown) and a significant increase at the age of 10 months. Our research revealed that BACE-1 levels increased mildly in early periods of hippocampal disorders, but they were severely increased later with aging. This increasing tendency of BACE-1 was consistent with the change in APP. This may contribute to the high levels of $A \beta$ in the brains of APP Tg mice. Icariin administration for 6 months significantly reduced the levels of BACE-1 expression in the hippocampus of APP V717I Tg mice at the age of 10 months. Inhibition of BACE-1 expression would be a novel target for icariin in $\mathrm{AD}$ treatment.

The $A \beta$ burden is related to both the excessive BACE-1 expression and the enhanced BACE-1 activity. In the present study, the activity of BACE-1 was not detected. However, in our previous study, we found that Epimedium flavonoids ( $>50 \%$ of which is icariin) decreased $A \beta$ production in APP cDNA-transfected SH-SY5Y neuroblastoma cells and inhibited $\beta$-secretase activity in vitro [34]. Since icariin accounts for $>50 \%$ of Epimedium flavonoids, there is the possibility that icariin can also inhibit BACE-1 activity, but this needs to be proved in the future study.

Besides BACE-1, the other key enzyme involved in the generation of $A \beta$ is $\gamma$-secretase, which is considered to have at least 4 integral membrane proteins, such as presenilin 1 (PS-1), nicastrin, APH1, and PEN2. Among them, PS-1 is the most important component in $\gamma$-secretase [35]. In our present study, PS-1 did not show obvious changes in the brains of APPV717I Tg mice at the age of 10 months, and icariin had no significant effects on PS-1 levels in the hippocampus of APP Tg mice after its administration for 6 months (data not shown).

\section{Conclusion}

The present study demonstrated that icariin reduced $A \beta$ contents and its deposition and decreased amyloid plaques in the hippocampus of APPV717I transgenic mice by decreasing the expression of APP and BACE-1, thus improved learning-memory abilities. These novel findings suggest that icariin may have the potential to block or retard the pathological progression of $\mathrm{AD}$. As an effective component of traditional Chinese medicine, icariin is promising for the prevention and treatment of AD.

\section{Acknowledgements}

This work was supported by the National Natural Science Foundation of China (Nos. 81274120, 81273498), the Beijing Natural Science Foundation (No. 7112061), the Beijing Key Foundation of Traditional Chinese Medicine (No. KJTS2011-04), the Capital Health Development Scientific Grant (No. 2011-1001-05), and the Beijing Health and Technical Personal of High-level Plan (Nos. 2009-3-66, 2011-1-7). We would like to thank Li Zhang and Hou-xi Ai for technical assistance.

\section{Abbreviations}

$\mathrm{AD}$, Alzheimer's disease; APP, amyloid precursor protein; $A \beta, \quad \beta$-amyloid; $\mathrm{BACE}, \quad \beta$-site APP-cleaving enzyme; $\mathrm{Tg}$, APPV717I transgenic.

\section{Competing Interests}

The authors have declared that no competing interest exists.

\section{References}

1. Wisniewski HM, Silverman W. Diagnostic criteria for the neuropathological assessment of Alzheimer's disease: current status and major issues. Neurobiol Aging. 1997; 18(4): 43-50.

2. Selkoe DJ. Alzheimer's disease: a central role for amyloid. J Neuropathol Exp Neurol. 1994; 53(5): 438-447.

3. Selkoe DJ. Translating cell biology into therapeutic advances in Alzheimer's disease. Nature. 1999; 399(6738 Suppl): A23-31.

4. Cai H, Wang Y, McCarthy D, et al. BACE1 is the major beta-secretase for generation of Abeta peptides by neurons. Nat Neurosci. 2001; 4 (3): 233-234.

5. Laird FM, Cai H, Savonenko AV, et al. BACE1, a major determinant of selective vulnerability of the brain to amyloid-beta amyloidogenesis, is essential for cognitive, emotional, and synaptic functions. J Neurosci. 2005; 25(50): 11693-11709.

6. Zhou L, Brouwers N, Benilova I, et al. Amyloid precursor protein mutation E682K at the alternative $\beta$-secretase cleavage $\beta$ '-site increases $A \beta$ generation. EMBO Mol Med. 2011; 3(5): 291-302.

7. Schenk D, Barbour R, Dunn W, et al. Immunization with amyloid-beta attenuates Alzheimer-disease-like pathology in the PDAPP mouse. Nature. 1999; 400(6740): 173-177.

8. Zhang L, Xing Y, Ye CF, et al. Learning-memory deficit with aging in APP transgenic mice of Alzheimer's disease and intervention by using tetrahydroxystilbene glucoside. Behav Brain Res. 2006; 173(2): 246-254.

9. Chen $\mathrm{KM}, \mathrm{Ge} \mathrm{BF}, \mathrm{Ma} \mathrm{HP}$, et al. Icariin, a flavonoid from the herb epimedium enhances the osteogenic differentiation of rat primary bone marrow stromal cells. Pharmazie. 2005; 60(12): 939-942.

10. Song $\mathrm{YH}, \mathrm{Cai} \mathrm{H}, \mathrm{Gu} \mathrm{N}$, et al. Icariin attenuates cardiac remodelling through down-regulating myocardial apoptosis and matrix metalloproteinase activity in rats with congestive heart failure. J Pharm Pharmacol. 2011; 63(4): 541-549.

11. $\mathrm{Xu} \mathrm{CQ}$, Liu BJ, Wu JF, et al. Icariin attenuates LPS-induced acute inflammatory responses: involvement of PI3K/Akt and NF-kB signaling pathway. Eur J Pharmacol. 2010; 642(1-3): 146-153. 
12. Zhou J, Wu J, Chen $\mathrm{X}$, et al. Icariin and its derivative, ICT, exert anti-inflammatory, anti-tumor effects, and modulate myeloid derived suppressive cells (MDSCs) functions. Int Immunopharmacol. 2011; 11(7): 887-895.

13. Ye LK, Chen JM, Liu SH, et al. Pharmacokinetics of icariin in rats. Chin Pharm J, 1999, 34(1): 33-36

14. Bao $Y$, Sun RG. Screening of effective ingredients of traditional Chinese herb Epimedium koreanum Nakai by combination of co-cultured ECV304 /C6 cells as an in vitro BBB model with HPLC-MS analysis. Chin J Biochem \& Mol Biol. 2012, 28(4):370-374

15. Wu B, Chen $\mathrm{Y}$, Huang J, et al. Icariin improves cognitive deficits and activates quiescent neural stem cells in aging rats. J Ethnopharmacol. 2012; 142(3): 746-753.

16. Nie J, Luo $\mathrm{Y}$, Huang $\mathrm{XN}$, et al. Icariin inhibits $\beta$-amyloid peptide segment 25-35 induced expression of beta-secretase in rat hippocampus. Eur J Pharmacol. 2010; 626(2-3): 213-218.

17. Urano T, Tohda C. Icariin improves memory impairment in Alzheimer's disease model mice (5xFAD) and attenuates amyloid $\beta$-induced neurite atrophy. Phytother Res. 2010; 24(11): 1658-1663.

18. Zhang J, Wu X, Qin C, et al. A novel recombinant adeno-associated virus vaccine reduces behavioral impairment and beta-amyloid plaques in a mouse model of Alzheimer's disease. Neurobiol Dis. 2003; 14(3): 365-379.

19. Sturchler-Pierrat C, Abramowski D, Duke M, et al. Two amyloid precursor protein transgenic mouse models with Alzheimer disease-like pathology. Proc Natl Acad Sci U S A. 1997; 94(24): 13287-13292.

20. Chang Y, Qin C, Yin HX, et al. Establishment of the transgenic model of Alzheimer disease. Acta Anatomica Sinica, 2000; 31(2): 144-147.

21. Karl T, Bhatiaa S, Cheng D, et al. Cognitive phenotyping of amyloid precursor protein transgenic J20 mice. Behav Brain Res. 2012; 228(3): 392-397.

22. Zhang L, Yu S, Zhang R, et al. Tetrahydroxystilbene glucoside antagonizes age-related $\alpha$-synuclein overexpression in the hippocampus of APP transgenic mouse model of Alzheimer's disease. Restor Neurol Neurosci. 2013; 31(1): 41-52.

23. Tanghe A, Termont A, Merchiers P, et al. Pathological hallmarks, clinical parallels, and value for drug testing in Alzheimer's disease of the APP[V717I] london transgenic mouse model. Int J Alzheimers Dis. 2010. doi: 10.4061/2010/417314.

24. Moechars D, Dewachter I, Lorent $\mathrm{K}$, et al. Early phenotypic changes in transgenic mice that overexpress different mutants of amyloid precursor protein in brain. J Bio Chem. 1999; 5(10): 6483-6492.

25. Vattemi G, Nogalska A, King Engel W, et al. Amyloid- $\beta 42$ is preferentially accumulated in muscle fibers of patients with sporadic inclusion-body myositis. Acta Neuropathol. 2009; 117(5): 569-574.

26. Tamagno E, Guglielmotto M, Aragno $M$, et al. Oxidative stress activates a positive feedback between the gamma- and beta-secretase cleavages of the beta-amyloid precursor protein. J Neurochem. 2008; 104(3): 683-95.

27. Rockenstein E, Torrance M, Mante M, et al. Cerebrolysin Decreases AmyloidProduction by Regulating Amyloid Protein Precursor Maturation in a Transgenic Model of Alzheimer's Disease. J Neurosci Res. 2006; 83(7):1252-1261.

28. Lim Y.A., Murray L.A., Lai M.K.P., et al. NeuroAiD ${ }^{\circledR}$ (MLC601) and Amyloid Precursor Protein Processing. Cerebrovasc Dis 2013;35(suppl 1):30-37

29. Zhou Z, Chan C H, Ma Q, et al. The roles of amyloid precursor protein (APP) in neurogenesis: Implications to pathogenesis and therapy of Alzheimer disease. Cell adhesion \& migration, 2011, 5(4): 280-292

30. Li F, Gong $\mathrm{QH}, \mathrm{Wu} \mathrm{Q}$, et al. Icariin isolated from Epimedium brevicornum Maxim attenuates learning and memory deficits induced by D-galactose in rats. Pharmacol Biochem Behav. 2010; 96(3): 301-305.

31. Luo Y, Nie J, Gong QH, et al. Protective effects of icariin against learning and memory deficits induced by aluminium in rats. Clin Exp Pharmacol Physiol. 2007; 34(8):792-795

32. Heneka MT, Sastre M, Dumitrescu-Ozimek L, et al. Focal glial activation coincides with increased BACE1 activation and precedes amyloid plaque deposition in APP[V717I] transgenic mice. J Neuroinflammation. 2005; 2: 22.doi:10.1186/1742-2094-10-61

33. Ling Y, Monrgank, Kalsheker N, et al. Amyloid precursor protein and the biology proteolytic processing: relevance to Alzheimer's disease. Int J Biochem Cell Biol. 2003; 35(11): 1505 -1535.

34. Yang $\mathrm{P}$, Song QJ, Wang $\mathrm{YH}$, et al. Effects of epimedium flavanoids on $\beta$-amyloid in APP695 cDNA-transfected nerve cells and on $\beta$-secretase activity in vitro. Chinese Journal of Rehabilitation Theory and Practice. 2009; 15: 126-128.

35. De Strooper B, Iwatsubo T, Wolfe MS. Presenilins and $\gamma$-secretase: structure, function, and role in Alzheimer disease. Cold Spring Harb Perspect Med. 2012; 2(1): a006304. 